\title{
A COMPARISON OF MONOCHROMATIC SCREENS FOR OPTICAL PYROMETRY.
}

BY

\section{W. E. FORSYTHE.}

IN working with any optical pyrometer it is generally sufficient to use a so-called monochromatic screen between the eye and the pyrometer filament or the comparison source in order that brightness comparisons can be made without trouble due to color differences. For the most part red glass screens have been used in the past, and the question is often asked-Why not use screens of other colors, as, for instance, a green or a blue screen? In connection with some other work quite a number of readings have been made with particular red, green and blue screens before the eyepiece of a disappearing-filament optical pyrometer. Since the above readings with the different glasses extended over

FIG. I.

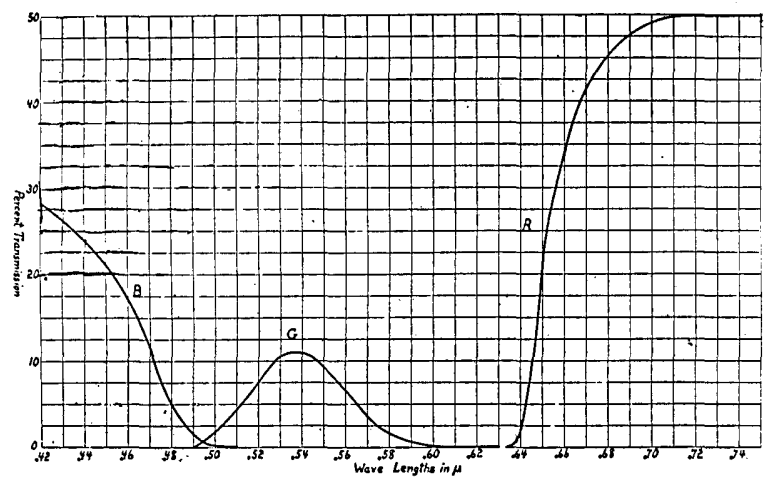

Spectral transmission of different screens.

Curve $B$, two thicknesses blue uviol glass, total thickness $3.9 \mathrm{~mm}$.

Curve $G$, two thicknesses green glass, total thickness $5.2 \mathrm{~mm}$.

Curve $R$, two thicknesses Jena red glass, total thickness $6.8 \mathrm{~mm}$.

a wide range of temperatures, it was thought worth while to make a study of these readings to see if settings made with any one of these glasses as the monochromatic screen were more accurate than with either of the others.

The spectral transmissions of the three glass screens used are shown in Fig. I. The red glass consisted of two thicknesses of 
Jena Glass (total thickness $6.8 \mathrm{~mm}$ ). This is the glass that has been used in Nela Research Laboratory as a standard red screen for pyrometric work for the past six or seven years. The green glass consists of two thicknesses (total thickness $5.2 \mathrm{~mm}$ ) of an unsaturated green glass that was obtained from Mr. Gage of the Corning Glass Works. The blue glass consisted of two pieces of blue uviol glass (total thickness $3.9 \mathrm{~mm}$ ).

In Table $I$ is given the percentage of the total light from a black body at different temperatures that is transmitted by each of these glasses. These values were obtained by calculation, using the following formula:

$$
T_{R}=\frac{\int_{0}^{\infty} J(\lambda T) v_{\lambda} T^{\prime} d \lambda}{\int_{0}^{\infty} J(\lambda T) V_{\lambda} d \lambda}
$$

where $J(\lambda T) d \lambda$ equals black-body energy as given by Wien's equation for the interval $\lambda$ to $\lambda+d \lambda, V_{\lambda}=$ visibility and $T^{\prime}$ the spectral transmission of the glass used. This integral can be calculated by the step-by-step method with sufficient accuracy for this purpose.

TABLE I.

Percentage of the Total Light from a Black Body ai Different Temperatures Transmitted by Different Glasses.

\begin{tabular}{|c|c|c|c|}
\hline \multirow[b]{2}{*}{ Temperature of black body } & \multicolumn{3}{|c|}{ Kind of glass } \\
\hline & $\begin{array}{c}\text { Jena red two } \\
\text { thicknesses }\end{array}$ & $\begin{array}{l}\text { Green two } \\
\text { thicknesses }\end{array}$ & $\begin{array}{c}\text { Blue uviol two } \\
\text { thicknesses }\end{array}$ \\
\hline 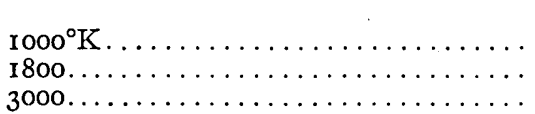 & $\begin{array}{l}\text { per cent. } \\
6.6 \\
2.1 \\
1.0\end{array}$ & $\begin{array}{l}\text { per cent. } \\
1.4 \\
3.2 \\
4.2\end{array}$ & $\begin{array}{l}\text { per cent. } \\
0.004 \\
.06 \\
.2\end{array}$ \\
\hline
\end{tabular}

The values given in Table I show very well one reason for the preference for the red glass at low temperature. It will be noticed that at $1000^{\circ} \mathrm{K}$, which is about as low as readings are generally made with the optical pyrometer, the red glass transmits much more of the light than does the green or blue glass. The table also shows why it is practically impossible to make readings through the two blue glasses at the very low temperature. At high temperatures the green glass transmits much more than does the red glass, but even the red glass as used on the pyrometer for 
temperature ranges, roughly $\mathrm{I} 500^{\circ}$ to $\mathrm{I} 800^{\circ} \mathrm{K}$, transmits enough light to very greatly tire the eye.

If two red glasses such as described are being used in the eyepiece to observe a source at a temperature of $2000^{\circ} \mathrm{K}$ and one is removed, about twice as much light will reach the eye as before. If for the same condition, the two green glasses are being used and one of them removed, about 4.3 times as much light will reach the eye as before; while about 5.5 times as much light is transmitted by one thickness of blue glass as is transmitted by two thicknesses. These ratios do not vary but a small amount for different temperatures of the source observed. Corning high transmission red ( 50 per cent.) is a somewhat better glass than the Jena Glass here used. There may be better green or blue glasses than the ones used here, but these are the best we have found. With any one of the three glasses here used, a single thickness will not give a color match when there is an intensity match between the pyrometer filament and the source being studied for a large temperature difference between them, that is, when a rotating sector of small transmission is used. It is, therefore, necessary to use two thicknesses of glass. Even with two thicknesses of the green glass a good color match is not obtained when using a sector of small transmission. However, it is possible to repeat the setting quite well with two of these green glasses. For low temperatures it does not make much difference in the readings whether one or two glasses are used. This difference between the readings for two red glasses and for one red glass amounts to about one degree near $1800^{\circ} \mathrm{K}$ and to somewhat less at I $500^{\circ} \mathrm{K}$, the reading being lower for one glass, for a tungsten pyrometer filament compared with a black body. For the blue glass for the same conditions the difference is somewhat greater, corresponding to about two degrees at $1800^{\circ} \mathrm{K}$ and to somewhat less at $\mathrm{I} 500^{\circ} \mathrm{K}$. At lower temperatures this difference for either glass is much less. The accuracy gained by having the greater amount of light far outweighs the small error due to the change in effective wave-length.

Effective Wave-length of Monochromatic Screen.-An optical pyrometer can be calibrated and so used as to make unnecessary a knowledge of the extent to which the screen is monochromatic. To do this requires a black-body furnace that can be operated at various temperatures up to the highest tem- 
perature for which the pyrometer is to be used. However, to use Wien's equation to extend the temperature scale, either above or below that of the standard furnace, by the use of a rotating sector disk or an absorbing glass, that is, to find the temperature of a black body having a brightness of, say, ten times (assuming a sector or absorbing glass transmission of one-tenth) that of a black body whose temperature can be measured directly, a knowledge of what wave-length to use, or the effective wave-

FIG. 2.

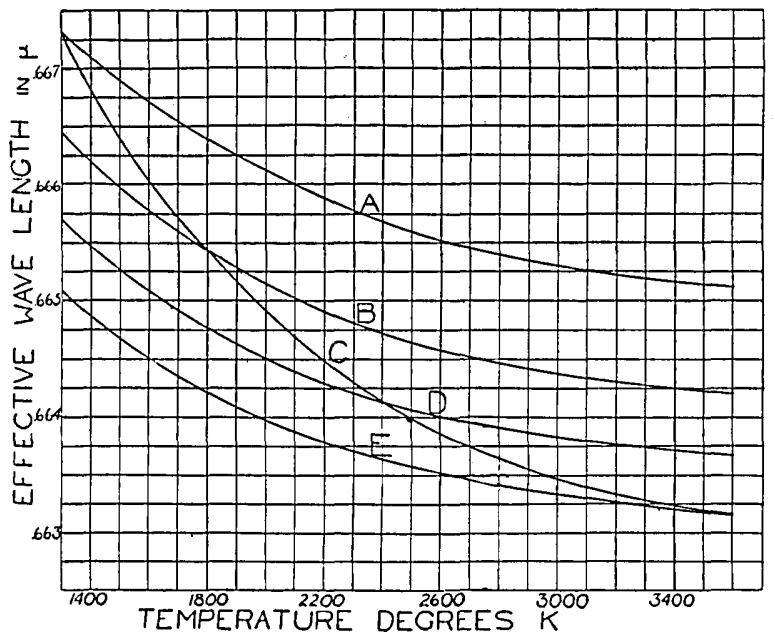

Effective wave-length for Jena red glass.

Curve $A$, effective wave-length from $I 300^{\circ} \mathrm{K}$ to other temperatures.

Curve $B$, effective wave-length from $I 800$ to other temperatures.

Curve $D$, effective wave-length from 2400 to other temperatures.

Curve $E$, effective wave-length from 3600 to other temperatures.

Curve $C$, limiting effective wave-length.

length, ${ }^{*}$ is necessary. The effective wave-length also must be known if the pyrometer is used to measure the temperature of non-black bodies. In using the pyrometer, it is the integral luminosities through the monochromatic screen that are compared, for which reason the effective wave-length of the screen corresponding to a certain temperature interval has been defined as the wave-length for that temperature interval of a black body, such that the ratio of its radiation intensities equals the ratio of the integral luminosities through the screeen used.

\footnotetext{
*Astrophy's. Jour., 42, p. 294, 1915.
} 
Knowing the spectral transmission of the glass, it is possible to calculate the effective wave-length $\lambda_{e}$ for any temperature interval by means of the following equation:

$$
\left[\frac{J\left(\lambda T_{1}\right)}{J\left(\lambda T_{2}\right)}\right]_{\lambda e}=\frac{\int_{0}^{\infty} J\left(\lambda T_{1}\right) V_{\lambda} t^{\prime} d \lambda}{\int_{0}^{\infty} J\left(\lambda T_{2}\right) V_{\lambda} t^{\prime} d \lambda}
$$

where $t^{\prime}$ is the spectral transmission of the glass and $V_{\lambda}$ is the visibility. These integrals also can be computed by the step-by-

FIG. 3.

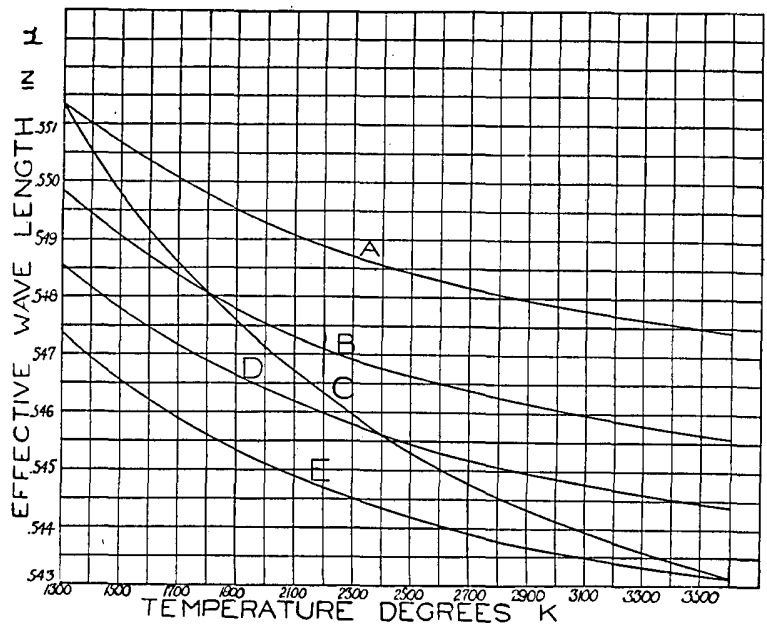

Effective wave-length of green glass.

Curve $A$, effective wave-length from $\mathrm{I} 300^{\circ} \mathrm{K}$ to other temperatures. Curve $B$, effective wave-length from $I 800$ to other temperatures.

Curve $D$, effective wave-length from 2400 to other temperatures.

Curve $E$, effective wave-length from 3000 to other temperatures.

Curve $C$, limiting effective wave-length.

step method with sufficient accuracy for this purpose. Using this equation, the effective wave-length was calculated for each of the glasses whose spectral transmission is shown in Fig. I for a number of temperature intervals and the results plotted as shown in Figs. 2, 3 and 4. These curves in addition to those in Fig. I show the characteristics of the three glass screens. It will be noted in Fig. 2 that the effective wave-length for the red glass for the temperature interval $\mathrm{I} 800^{\circ} \mathrm{K}$ to $3000^{\circ} \mathrm{K}$ is $0.6659 \mu$. The effective wave-length for the green and the blue glass screens for the same interval (Figs. 3 and 4 ) are respectively $0.5478 \mu$ and 
$0.4677 \mu$. If it is desired to find the effective wave-length for some other temperature interval-as $2000^{\circ} \mathrm{K}$ to $2900^{\circ} \mathrm{K}$-for which the curve is not drawn, the curve can be imagined drawn parallel to the $1800^{\circ} \mathrm{K}$ curve, one point being determined where the curve for the limiting effective wave-length crosses the ordinate for this temperature. The desired effective wave-length will be given by the point where this curve would cross the ordinate for the other temperature, in this case, the $2900^{\circ} \mathrm{K}$ ordinate.

When making a set of readings with the optical pyrometer the method used is first with the pyrometer filament darker than the background to get a brightness match by increasing the pyrome-

FIG. 4.

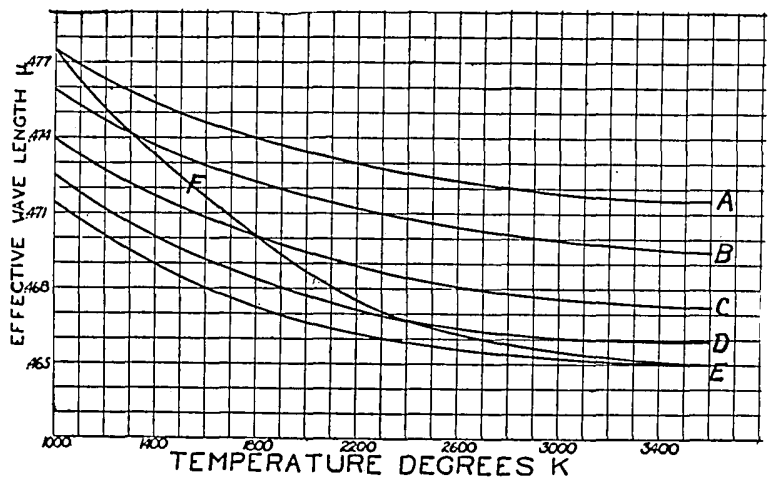

Effective wave-length for blue glass.

Curve $A$, effective wave-length from $1000^{\circ} \mathrm{K}$ to other temperatures. Curve $B$, effective wave-length from $I_{300}$ to other temperatures. Curve $C$, effective wave-length from I 800 Curve $D$, effective wave-length from 2400 Curve $E$, effective wave-length from 3600 to other temperatures. Curve $F$, limiting effective wave-length.

ter current. This is called a dark reading. The next brightness match is made starting with the pyrometer filament brighter than the background. This setting is called a bright reading. The average of a dark and a bright is what is called a reading. Three or four such averages constitute a set. The readings that are used to study the accuracy consist of two or three such sets where each set consists of the average of six separate brightness matches. The different sets were obtained by making first a set with the red glass, then one with the green glass, and finally a set with the blue glass. These were then repeated in the same order. A study of the readings thus obtained showed that for brightnesses 
corresponding to temperatures above $1400^{\circ} \mathrm{K}$ or $1500^{\circ} \mathrm{K}$ the range in the averages of the currents for the condition of balance was about the same, whether a red, green or blue glass was usec1. The percentage range in the readings are given in Table II.

TABLE II.

Percentage Range in Current Through Pyrometer Filament for Brightness Matches with the Background Under Various Conditions and for Different Colored Screens in the Eyepiece.

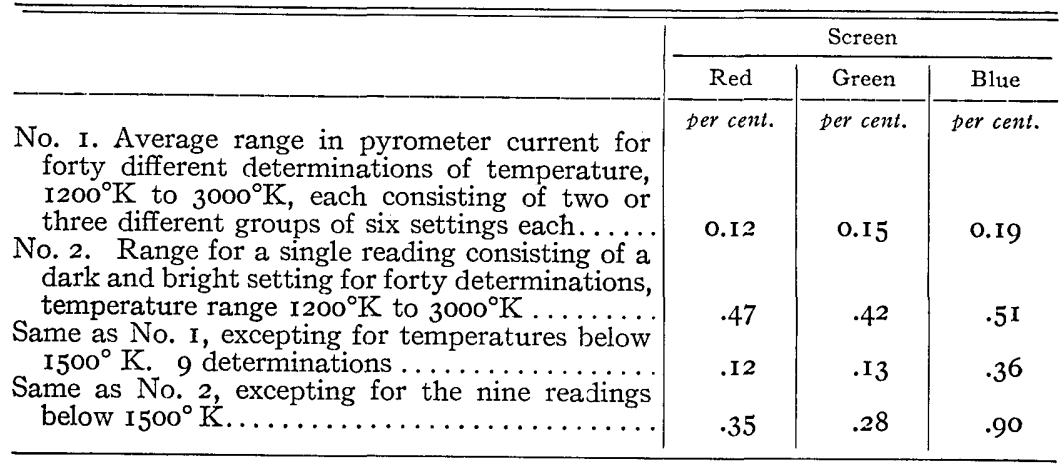

For the temperature range covered by this investigation, the relation between the percentage variation of the current through the pyrometer filament and the corresponding percentage variation in the temperature of the source being investigated for a brightness match is very nearly a constant independent of the temperature. It was also found that the constant was about the same for readings made with either of the three glasses. The result was that $\frac{\mathrm{dI}}{\mathrm{I}}=\frac{\mathrm{I} .8 \mathrm{dT}}{\mathrm{T}}$ where the constant $\mathrm{r} .8$ does not vary more than a few per cent. in going from the red to the blue. Thus, the per cent. variation in current divided by $\mathrm{r} .8$ will give the per cent. variation in the temperature. As can be seen from the data in Table II, the average range for the pyrometer currents for all temperature measured was very nearly the same for the readings with each of the three glasses and amounted to about 0.15 per cent. This makes the average range in the temperature measured less than one-tenth of a per cent., or less than $2^{\circ} \mathrm{C}$ for a temperature of $2000^{\circ} \mathrm{K}$.

The data in Table II show that for temperatures below $1500^{\circ} \mathrm{K}$, the readings with the blue glass had a range about three times as great as the readings with the red or green glass. 
In the table is given also the average range due to a single measurement consisting of the average of a dark and a bright reading. The average range in pyrometer current for the forty temperature determinations was about 0.5 per cent., which makes the temperature range due to a single measurement about $5^{\circ}$ at $2000^{\circ}$. Some of the readings, of course, showed a range somewhat greater than this. It must be remembered that this range corresponds to the greatest difference between any two readings (consisting of the average of a dark and a bright brightness match) for eight or ten readings. These results are thought to be pretty good and to indicate about the accuracy to be expected in this class of work. The results on the green glass show that the average for a single reading is less for the low temperatures than for the average of all the readings taken. This is due to the fact that many of the readings at high temperature were taken with a rotating sector and trouble due to poor color match was experienced. When a sector was used the current through the pyrometer was such that it corresponded to a temperature about $\mathrm{I} 500^{\circ} \mathrm{K}$ or higher.

To find out how different observers would agree in their readings, using the different colored screens, a number of readings were made by different observers. The brightness temperature of a tungsten lamp filament was measured at four different temperatures, using in turn each of the three glasses. The use of a tungsten lamp gives a greater brightness for the green and blue than would be obtained if a black body had been used at a temperature the same as this red brightness temperature. The brightness as observed at the blue end was increased by using a larger opening before the eyepiece telescope of the pyrometer, since it was found that readings could be made with this larger opening. The opening used with the red and green glasses was $9 \mathrm{~mm}$ in diameter, while for the blue glass the opening was $\mathrm{I} 2 \mathrm{~mm}$ in diameter. Seven observers made readings for the test. The first four, as they are arranged in Table III, had had much experience with the optical pyrometer, using different colored screens. Observer No. 5 had had considerable experience with a commercial form of the disappearing-filament pyrometer using red glass. Observer No: 6 had had a small amount of experience, having read once before in a test of this kind. Observer No. 7 had had no previous experience with this kind of work. The first readings were made 
on the lamp at a temperature of $1774^{\circ} \mathrm{K}$, then at $2154^{\circ} \mathrm{K}$, and finally at $1456^{\circ} \mathrm{K}$. At a later date the apparatus was again set up and most of the observers made readings with the tungsten lamp at a brightness temperature of $1245^{\circ} \mathrm{K}$. The temperature $2 \mathrm{I} 54^{\circ} \mathrm{K}$ was measured, using a $2^{\circ}$ rotating sector disk between the pyrometer lamp and the lamp filament being measured. This made the current readings for the $2154^{\circ} \mathrm{K}$ point of the same order as for the $1456^{\circ} \mathrm{K}$.

TABLE III.

Settings by Individual Observers Using Different Monochromatic Glass Screens.

\begin{tabular}{|c|c|c|c|c|c|}
\hline \multirow{2}{*}{ Observer } & \multirow{2}{*}{ Screen used } & \multicolumn{4}{|c|}{$\begin{array}{l}\text { Current through pyrometer filament for apparent } \\
\text { brightness match with tungsten filaments at the } \\
\text { following brightness temperatures }\end{array}$} \\
\hline & & $\begin{array}{l}\mathrm{I} 245^{\circ} \mathrm{K} \text {. } \\
\text { direct }\end{array}$ & $\begin{array}{l}\mathrm{I} 456^{\circ} \mathrm{K} \\
\text { direct }\end{array}$ & $\begin{array}{c}\text { I } 774^{\circ} \mathrm{K} \\
\text { direct }\end{array}$ & $\begin{array}{c}2 \mathrm{I} 54^{\circ} \mathrm{K} \\
2^{\circ} \text { sector }\end{array}$ \\
\hline WEF & Red glass. . . . . . . . & 2669 & 3353 & 4773 & 3197 \\
\hline $\mathrm{AGW}$ & Red glass. . . . . . . . . & $\ldots$ & 3358 & 4775 & 3193 \\
\hline $\mathrm{CHS}$ & Red glass. . . . . . . . & 2665 & 3362 & 4780 & 3188 \\
\hline IAV & Red glass. . . . . . . . & 2671 & 3357 & 4778 & 3190 \\
\hline $\mathrm{FH}$ & Red glass. . . . . . . . & 2667 & 3356 & 4774 & 3212 \\
\hline $\mathrm{FG}$ & Red glass. . . . . . . . & 2672 & 3363 & 4780 & 3185 \\
\hline \multirow[t]{2}{*}{$\mathrm{HP}$} & Red glass . . . . . . . . & 2670 & $335 \mathrm{I}$ & 4770 & 3199 \\
\hline & Mean... & 2669 & $335^{8}$ & 4776 & 3195 \\
\hline WEF & Green glass. . . . . . . & 2696 & 3393 & 4855 & 3619 \\
\hline AGW & Green glass. & $\cdots$ & 3394 & 4852 & 3609 \\
\hline CHS & Green glass. . & 2687 & 3393 & 4863 & 36 I 5 \\
\hline $\mathrm{IAV}$ & Green glass. . . . & 2693 & 3398 & 4854 & 3617 \\
\hline $\mathrm{FH}$ & Green glass. . . . & 2692 & 3398 & 4858 & 3631 \\
\hline FG & Green glass.... & 2710 & 3384 & 4858 & 3605 \\
\hline \multirow[t]{2}{*}{$\mathrm{HP}$} & Green glass. . . . . . . & $269 \mathrm{I}$ & 3410 & 4841 & $36 r 5$ \\
\hline & Mean....... & 2695 & 3394 & 4854 & $36 \mathrm{I} 6$ \\
\hline WEF & Blue glass..... & 2720 & 3407 & 4882 & 3974 \\
\hline $\mathrm{AGW}$ & Blue glass... & $\ldots$ & 3413 & 4884 & 3969 \\
\hline CHS & Blue glass..... & 2695 & $34 \mathrm{I} 4$ & 4888 & 3982 \\
\hline IAV & Blue glass.... & 2710 & 3412 & 4888 & 3966 \\
\hline $\mathrm{FH}$ & Blue glass... & 2707 & 3418 & 4894 & $396 I$ \\
\hline $\mathrm{FG}$ & Blue glass... & 2795 & 3429 & 4893 & 3979 \\
\hline \multirow[t]{2}{*}{$\mathrm{HP}$} & Blue glass... & 2722 & 3406 & 4766 & 3901 \\
\hline & Mean... . & 2725 & $34 \mathrm{I}^{\circ}$ & 4885 & 397 I \\
\hline
\end{tabular}

These readings were made by the method described above. Each observer made but a single set of readings, consisting of six brightness matches at a particular temperature. The average of the current obtained by each observer is given in Table III. It will be noticed that the agreement is very good for the three highest temperatures and about the same for each of the screens used. For the lower temperatures the best agreement among the 
different observers is found in the case where the red glass was used; also the agreement for the green glass is much better than for the blue glass.

For the readings on the $1240^{\circ} \mathrm{K}$ point a change of about $0.0003 \mathrm{amp}$. in the pyrometer current corresponds to one degree in temperature and for the $1456^{\circ} \mathrm{K}$ point a change of $0.0004 \mathrm{amp}$. in pyrometer current corresponds to about one degree in temperature. For the $1774^{\circ} \mathrm{K}$ point a change of one degree in temperature requires a change of $0.0005 \mathrm{amp}$. in pyrometer current, while for the $2154^{\circ} \mathrm{K}$ point a change of 0.0004 amp. corresponds to a change of about $3^{\circ}$. The reason for this greater change is due to the use of the rotating sector with small transmission.

From the results of the tests shown for all readings except at low temperatures it would be pretty hard to decide whether the green or red glass screen was the better, but the data show very definitely that the readings with the blue glass are not so good as those with the red or green. For very low temperatures it was almost impossible to make readings with the blue glass. For temperatures below $\mathrm{I} 200^{\circ} \mathrm{K}$, and thus very low brightnesses, there is no question but that the red glass is the best to use. For temperatures in the neighborhood of $1400^{\circ} \mathrm{K}$, the readings with the red and green glass have about the same range and this is somewhat greater than 0 .I of one per cent. The readings for the blue glass are very erratic and the range in some cases is several times this amount, the average being about three or four times this amount. Excepting at very low temperature (i.e., below say $1200^{\circ} \mathrm{K}$ ) there is no question of the amount of light obtained since either the red or green glass transmitted sufficient light for brightness matching. Personal preference will have considerable influence on this decision. The observers who made readings on these tests were about equally divided in their preference for the red or green glass screens. To the author, the fact that good color matches are not obtained under all conditions with the green glass would be against this glass.

There are four reasons for choosing the red glass rather than the green. In the first place, at low temperatures, the red radiation first becomes visible and thus readings may be made at a somewhat lower temperature with the red glass. This is well shown in Table $I$. In the second place, the color change for a change in wave-length is much less in the red part of the spectrum 
than in the green, which makes the red the better part of the spectrum for this work. This is shown by the fact that for the green glass here used, a good color match is not obtained when a sector of small transmission is used, while no such trouble is found with the red glass. The third reason for using red glasses as monochromatic screens is that better red screens can be obtained, that is, the spectral transmission of the red screens ends with a steeper slope than does the green screen. This is illustrated very well by the relative slopes of the curves showing the spectral transmission of the red and green glass shown in Fig. I. These curves show that the transmission of the red glass is very steep on the short wave-length side and the other side being at the limit of the visible spectrum, the very rapid falling off of the visibility curve in this region makes the luminosity curve steep on that side.

The fourth advantage of the red screen is that when measuring a temperature so high that a rotating sector or absorbing glass is necessary, the transmission of the sector or absorbing glass that must be used is larger for the longer wave-length than it is for the short wave-length. From Wien's equation the following relation can be derived between the wave-length and the transmission ( $t$ ) of the sector used for extrapolating to a higher temperature.

$$
\frac{\log t_{1}}{\log t_{2}}=\frac{\lambda_{1}}{\lambda_{2}}
$$

Suppose that it is necessary to measure a temperature of $3100^{\circ} \mathrm{K}$, using a pyrometer lamp or other comparison source that cannot be heated to a higher brightness than that corresponding to $I 800^{\circ} \mathrm{K}$. If the red glass described above is used, the transmission of the absorbing glass or sector that must be used is about 0.0054 . For the green glass this same temperature range requires a sector or absorbing glass with a transmission of about o.0oI7, while a sector or absorbing glass with a transmission of about 0.0006I is required for the blue glass described above. Such small transmissions are very hard to measure and thus it is better to use the red glass when measuring very high temperatures.

Nela Research Laboratories,

Nela Park, Cleveland, Ohio,

December, I920.

Vol. V, No. I-7 